\title{
Q1 Electricity generation from a biomass cookstove with MPPT power management and passive liquid cooling
} \\ M.J. Deasy ${ }^{\text {a }}$, S.M. O'Shaughnessy a,* , L. Archer ${ }^{\text {b }}$, A.J. Robinson ${ }^{\text {a }}$ \\ ${ }^{a}$ Department of Mechanical \& Manufacturing Engineering, Parsons Building, Trinity College Dublin, Ireland \\ b United Purpose, Green Heritage House, Area 13, Plot 13/80, P.O. Box 159, Lilongwe, Malawi
}

\section{A R T I C L E I N F O}

\section{Article history:}

Received 15 September 2017

Revised 11 January 2018

Accepted 11 January 2018

Available online xxxx

\section{Keywords:}

Energy

Thermoelectric generator

Electricity generation

Biomass cookstove

Sustainable development

Thermosiphon

Passive cooling

Liquid cooling

\begin{abstract}
A B S T R A C T
An electrical power generator for use with biomass cooking stoves has been developed. The design is intended for 17 users in developing countries who lack regular access to electricity. Electricity is generated based on the thermo- 18 electric effect. A bespoke heat collector captures heat from the combustion chamber of the cooking stove and 19 transfers it to a single thermoelectric generator (TEG) module. To maintain a sufficiently high temperature differ- 20 ence across the TEG, heat is dissipated using a passive single phase liquid thermosiphon system. This cooling 21 system eliminates the requirement for mechanical components such as fans or pumps, which are unreliable 22 and draw significant electrical power. In a controlled laboratory setting, a maximum power of $5.8 \mathrm{~W}$ has been 23 produced from a single TEG installed into a low cost ceramic cooking stove currently disseminated in large num- 24 bers in Malawi, Africa. The TEG power is controlled using a maximum power point tracking (MPPT) conditioning 25 circuit with an estimated efficiency of $\sim 70 \%$. The circuit provides a stable $5 \mathrm{~V}$ output via a USB connector for charg- 26 ing mobile phones, lights, power banks and other devices. Experiments have shown that the device is capable of 27 performing for extended periods without significant reduction in performance. The magnitude of the power gen- 28 erated by this passive cooling system is observed to be comparable to that delivered by similar TEG-stove systems 29 driven by active cooling. An average power generation of over $4 \mathrm{~W}$ was achieved which, including circuit 30 efficiency, provided $\sim 10 \mathrm{~W} \cdot \mathrm{h}$ of useful electrical energy over a $4 \mathrm{~h}$ burning interval, which is sufficient for 31 charging low powered electrical appliances. Five prototypes fitted with data measurement and acquisition 32 were deployed to families in rural Malawi in order to evaluate real-life performance of the technology. Initial 33 field-trial results have advocated the viability of the TEG-stove technology for charging low powered electronic 34 devices typically used in developing countries such as Malawi.
\end{abstract}

(C) 2018 Published by Elsevier Inc. on behalf of International Energy Initiative. 36

\section{Introduction}

A thermoelectric generator, or TEG, is a solid state semi-conductor device which converts heat directly into electricity via the thermoelectric effect. The efficiency of thermoelectric devices is typically $<7 \%$, but the simple construction and absence of moving parts makes them extremely reliable in many circumstances. TEGs are versatile and can be found in a wide variety of space, automotive, military and domestic applications to name but a few (Elghool et al., 2017), and have risen in popularity due to their use in waste heat-to-power generation applications.

Research into the use of thermoelectric generators with cooking stoves has increased over the last thirty years. A comprehensive review of the development of stove-powered thermoelectric generators is provided in ref. (Gao, Huang, Li, Qu, \& Zhang, 2016). To produce electricity

\footnotetext{
* Corresponding author.

E-mail addresses: Lloyd.Archer@united-purpose.org (L. Archer), arobins@tcd.ie (A.J. Robinson).
}

from a TEG, a temperature difference must be maintained between its 64 heated and cooled faces. In the majority of cases involving stoves used 65 in a domestic environment, heat is extracted from the fire primarily 66 by conduction and radiation. This can be achieved by a protrusion into 67 the fire (O'Shaughnessy, Deasy, Doyle, \& Robinson, 2015a, 2015b; 68 Raman, Ram, \& Gupta, 2014; Stokes, Mantini, Chartier, \& Rodes, 2012), 69 or by attaching the TEG to a solid, hot boundary (Killander \& Bass, 70 1996; Lertsatitthanakorn, 2007; Mastbergen, Willson, \& Joshi, 2005; 71 Nuwayhid, Rowe, \& Min, 2003; Nuwayhid, Shihadeh, \& Ghaddar, 72 2005). To cool the TEG, a wide variety of different cooling systems 73 have been investigated. The cooling methods can be categorised based 74 on the working fluid and on their dominant heat transfer mode. $\quad 75$

A recent review by Gao et al. (2016) found that air-cooled forced 76 convection is the most common and straightforward technique, where 77 the cold heat sink of the thermoelectric generator is cooled by air pro- 78 vided by a fan. Fan-cooled systems can achieve low thermal resistances 79 using a small number of components, and the air can also be routed to 80 the combustion chamber to aid the combustion process. However, a 81 moving part is required which can break down leading to total power 82 
83

84

85

86

87

88

89

90

91

92

93

94

95

96

97 generation system failure, and extra circuitry is required to control the operation of the fan, which is typically powered using some of the electricity generated by the TEG.

Forced convection air cooling systems have been employed by the authors in previous studies (O'Shaughnessy, Deasy, Doyle, \& Robinson, 2014; O'Shaughnessy, Deasy, Kinsella, Doyle, \& Robinson, 2013). In these examples a heat pipe heatsink normally used for CPU cooling was equipped with an adapted low power fan, driven by a portion of the power generated by the TEG. This proved effective in terms of TEG power production and fan power consumption and there was an excess of energy produced compared to what was used for phone and LED (light emitting diode) lantern charging. However, the overall cost and complexity of this technology demonstrator was too high for developing world technology and the power draw to run the fan was nonnegligible. User feedback also indicated that the generator was bulky and cumbersome.

The authors adapted their design based on user feedback and developed a lower cost and smaller form factor generator, albeit one which produced less power than previous designs (O'Shaughnessy et al., 2015a). The design again used forced convection cooling and achieved adequate power generation initially, but failure eventually occurred due to a combination of low power generation and a depleted internal battery caused by simultaneously charging and discharging. This had the knock-on effect that the fan-fin cooling system operation was also compromised which led to slow fan speed and eventual melting of the fan casing and overheating of the TEG. Here, the simple yet functional charge control circuitry developed by Kinsella, O'Shaughnessy, Deasy, Duffy, and Robinson (2014) was not capable of coping with user in-field behaviour indicating that a 'smarter' circuit is required. Again, the power draw by the fan did consume a non-negligible amount of the limited electrical energy produced by the TEG.

The TEG power draw relating to fluid circulation become quite significant in forced liquid convection systems which typically use water as the working fluid. Much of the TEG-related research in this area has focused on cogeneration applications with domestic boilers, such as studies in refs. (Brazdil \& Pospisil, 2013; Qiu \& Hayden, 2011; Rowe et al., 1997). The advantages of such systems is that the pump and pipe network is typically already in place. For standalone power generation from cooking stoves, pumped liquid systems are much rarer. Goudarzi et al. (2013) used 21 TEGs in a $7 \times 3$ configuration, and liquid water was pumped at high flow rates through cooling blocks. Each TEG was capable of producing $16 \mathrm{~W}$. At a maximum fuel consumption rate of $9 \mathrm{~kg}$ of wood per hour, an average power output of $7.9 \mathrm{~W}$ per TEG was achieved, which did not account for the $\sim 5 \mathrm{~W}$ of power required by the pump. However, it appears that their system is open loop which means that a continuous supply of cold water is required to achieve the stated power output.

Passive cooling systems of TEG systems are desirable because they have no moving parts (pumps, fans etc.) which increases long term reliability and does not draw on the comparatively low power produced by a TEG system. Furthermore, they solve the paradoxical situation encountered whereby powered cooling systems must be active in order for the TEG to generate sufficient electricity to power them. To this end, some systems have employed natural convection with air as the coolant. However, the poor thermal properties of air result in the requirement of inappropriately large air-side heat sinks, which are generally low performance, cumbersome and expensive. For example, Nuwayhid et al. (2005) fitted a thermoelectric generator to the side of a domestic woodstove in rural Lebanon. The generator was driven using one or more thermoelectric modules. Cooling was achieved using a high performance fin type heat sink exposed to the surrounding air. Using a single module that was capable of producing over $16 \mathrm{~W}$, the maximum steady state matched load power was determined to be only $4.2 \mathrm{~W}$, with the difference being due to the high thermal resistance of the air-side heat sink. Nuwayhid and Hamade (2005) investigated the viability of a two phase thermosyphon, whereby the heat is transported and spread evenly over a significant air-side surface area exposed to 149 ambient air via condensation. The system included a HZ-20 module 150 capable of $19 \mathrm{~W}$ of power generation. In their study Nuwayhid and 151 Hamade achieved only 3.4 W of electrical power at matched load in a 152 laboratory setting for the same reasons as Nuwayhid et al. (2005). 153 Furthermore, the cooling system was disproportionately large and 154 complicated to manufacture, making its viability questionable in the 155 developing world context.

Natural convection systems using water have also been investigated. 157 Water cooling systems have a lower thermal resistance than air due to 158 the liquid's more favourable thermophysical properties. In some 159 circumstances the systems are intended as cogeneration systems that 160 simultaneously generate electric power and heat for domestic hot 161 water use. This typically involves a large water reservoir in direct contact 162 with the cold heat sink, such as in studies by Nuwayhid, Moukalled, 163 AbuSaid, and Daaboul (2000) and Champier, Bedecarrats, Rivaletto, and 164 Strub (2010), Champier et al. (2011). In ref. (Champier et al., 2010) the 165 authors used up to four TEG modules, each capable of $10.5 \mathrm{~W}$, but the 166 maximum total power output was only $7 \mathrm{~W}$ at a temperature difference 167 of $160{ }^{\circ} \mathrm{C}$. In (Champier et al., 2011), a maximum 9.5 W was generated 168 from a single TEG capable of producing $16.2 \mathrm{~W}$. The authors stated 169 that the difficulty is to find a solution which can be used in developing 170 countries and not only in a laboratory.

Despite the various TEG cooling mechanisms studied, few studies 172 consider a fully integrated TEG-stove system which must include 173 some form of power control circuitry. A previous study by Kinsella 174 et al. (2014), implemented in the aforementioned field trials 175 (O'Shaughnessy et al., 2013, 2014, 2015a), showed that it is possible 176 to achieve high circuit efficiencies without the use of maximum power 177 point tracking (MPPT) by carefully matching the load resistance to the 178 internal resistance of the particular thermoelectric module. In that 179 study, a rechargeable lithium iron phosphate battery was used to store 180 the power generated by a single TEG. However, this approach limits 181 the range of applicable TEGs and batteries. Furthermore, reasonable 182 efficiencies were only achievable with a TEG temperature difference of 183 approximately $150{ }^{\circ} \mathrm{C}$. At lower temperature differences the efficiency 184 decreased significantly. Regardless of the simplicity of the approach, 185 the rechargeable battery significantly increased the cost of the overall 186 generator system and required significant training of end users to 187 avoid misuse which could damage the battery. To address these issues, 188 a new MPPT conditioning circuit was developed. MPPT provides the 189 ability to generate maximum power from a TEG independent of the 190 TEG temperature and the load resistance, effectively electrically 191 decoupling the TEG from the load that is charging. It is noted that 192 MPPT circuits require electrical power to operate at the compromise 193 of system efficiency when a TEG internal resistance matches the 194 effective resistance of the load. MPPT circuits more than make up for 195 this by continually providing maximum power regardless of the load 196 resistance associated with the charging electrical appliance.

\section{Objectives}

The use of a single phase thermosyphon to cool TEGs for power gen- 199 eration in a developing world has not been studied extensively. Many 200 studies that consider TEGs for use in stoves are laboratory based, and 201 only a few actually integrate the TEG with the stove. Even fewer study 202 the performance of the entire system including the stove, TEG, electrical 203 circuitry, heat collector and cooling method. The principal objective of 204 this work is to develop and test a fully integrated TEG-stove system, in- 205 cluding a modified low cost stove, passive heating and cooling systems 206 and MPPT circuitry. The design must be capable of producing sufficient 207 voltage and electrical energy from normal cooking practices so that 208 users can charge devices such as mobile phones, rechargeable batteries, 209 LED lanterns and radios on a daily basis. The magnitude of the power 210 generated by the passive system must be comparable to that delivered 211 by similar TEG-stove systems driven by active cooling. Additionally, 212 
the full system should be tested in a manner that is representative of how it will be used in the field. Furthermore, the system must be robust and low-cost as the targeted environment can be considered harsh and the end-users will be economically vulnerable.

\section{Nomenclature}

\begin{tabular}{lll}
\hline Symbol/acronym & Description & Unit \\
\hline$\alpha_{\text {eff }}$ & Effective Seebeck co-efficient & $\mathrm{V} / \mathrm{K}$ \\
$\mathrm{Bi}_{2} \mathrm{Te}_{3}$ & Bismuth telluride & - \\
$P_{\text {elec }}$ & Electrical power & $\mathrm{W}$ \\
$R_{L}$ & Electrical resistance of load & $\Omega$ \\
$R_{\text {TEG }}$ & Electrical resistance of TEG & $\Omega$ \\
$\Delta T_{T E G}$ & TEG temperature difference & $\mathrm{K}$ \\
$V_{O C}$ & TEG open circuit voltage & $\mathrm{V}$ \\
$V_{\text {TEG }}$ & TEG voltage & $\mathrm{V}$ \\
CPU & Central processing unit & - \\
DC & Direct current & - \\
LED & Light-emitting diode & - \\
MOSFET & Metal-oxide-semiconductor field-effect transistor & \\
MPP & Maximum power point & - \\
MPPT & Maximum power point tracking & - \\
PIC & Programmable Interface Controller & - \\
RTD & Resistance temperature detector & - \\
SD & Secure digital & - \\
SEPIC & Single ended primary inductor convertor & - \\
TEG & Thermoelectric generator & - \\
USB & Universal serial bus & - \\
\hline & & \\
\hline
\end{tabular}

\section{TEG theory and module parameters}

The Seebeck effect is a phenomenon by which a voltage difference is produced between two dissimilar electrical conductors or semiconductors in response to a temperature difference between them. TEGs operate 222 based on this effect and a voltage is generated when the two faces of 223 the TEG are at different temperatures.

As depicted in Fig. 1, TEGs are intended to be thermally oriented so 225 that heat is supplied to the 'hot' face whilst simultaneously dissipated 226 from the 'cold' face. A TEG therefore produces electrical power in 227 response to a temperature differential across the module as heat is 228 forced to flow between them. The electrical power output by the TEG 229 also depends on the electrical load resistance, $R_{L}$ (Fig. 1). A full descrip- 230 tion of TEG behaviour can be found in (Högblom \& Andersson, 2016; 231 Hsu, Huang, Chu, Yu, \& Yao, 2011; O'Shaughnessy et al., 2013; Rowe, 232 1978). It is easily shown that the power produced by the TEG, $P_{\text {elec }}$, is 233 given as

$$
\mathrm{P}_{\text {elec }}=\left(\alpha_{\text {eff }} \Delta \mathrm{T}_{\mathrm{TEG}}\right)^{2} \frac{\mathrm{R}_{\mathrm{L}}}{\left(\mathrm{R}_{\mathrm{L}}+\mathrm{R}_{\mathrm{TEG}}\right)^{2}}
$$

where $\alpha_{\text {eff }}$ is the effective Seebeck coefficient, $\Delta \mathrm{T}_{\mathrm{TEG}}$ is the temperature difference across the TEG module and $\mathrm{R}_{\mathrm{L}}$ and $\mathrm{R}_{\mathrm{TEG}}$ are the resistances of 237 the load and TEG respectively. From Eq. (1) it can be shown that the 238 maximum power is produced at matched load, which gives justification 239 for the requirement of MPPT circuitry in application.

The power generation system described in this study is designed for 241 operation with a single $7.2 \mathrm{~W}$ nominal power TEG module, although it is 242 suitable and scalable for use with larger, more powerful TEGs and/or 243 multiple modules. The chosen TEG is the TEG1B-12610-5.1 module, 244 supplied by TECTEG. The specifications for the TEG used in this study 245 are given in Table 1.

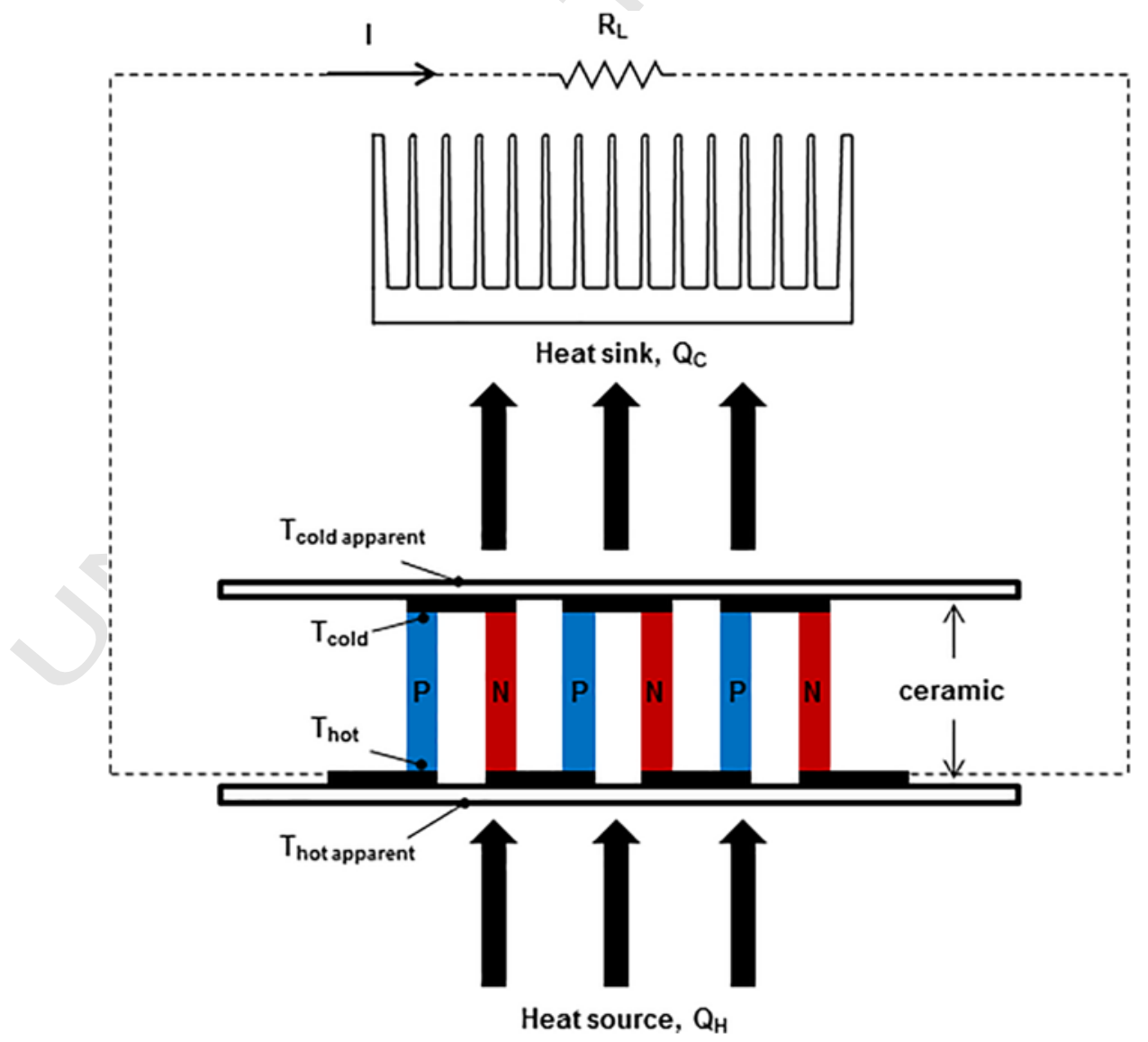

Fig. 1. Thermoelectric power generation. 
t1.1 Table 1

t1.2 TEG specifications at a cold side temperature of $30^{\circ} \mathrm{C}$.

\section{t1.3 Type}

t1.4 Max. hot side temperature

t1.5 Dimensions

t1.6 Open circuit voltage

Internal resistance

Matched load output voltage

Matched load output current

Matched load max. output power

Heat flow through the module

\section{$\mathrm{Bi}_{2} \mathrm{Te}_{3}$}

$300{ }^{\circ} \mathrm{C}$

$40 \mathrm{~mm} \times 40 \mathrm{~mm}$

$7.2 \mathrm{~V}$

$1.8 \Omega$

$3.6 \mathrm{~V}$

$2 \mathrm{~A}$

$7.2 \mathrm{~W}$

$\sim 148 \mathrm{~W}$

\section{TEG-stove design overview}

Although the design is intended to be adaptable to a variety of biomass-fed cooking stoves used in developing countries, for performance evaluation it was deemed appropriate to integrate the design into a mass produced low cost stove, and one which has been previously investigated by the current authors in Malawi, Africa (O'Shaughnessy et al., 2013, 2014, 2015a, 2015b).

\section{The cookstove}

A modified chitetezo mbaula (translated as 'protection stove') is used in this investigation and is shown in Figs. 2 and 3. This is a clay stove with thick walls, handles for portability and a pot rest which can accommodate different pot sizes. For this work, the stove has been modified to include an opening opposite to the firewood port for integration of the TEG system. A stove manufacturing facility was established in a rural village in the Thyolo district of Malawi to manufacture the stoves for

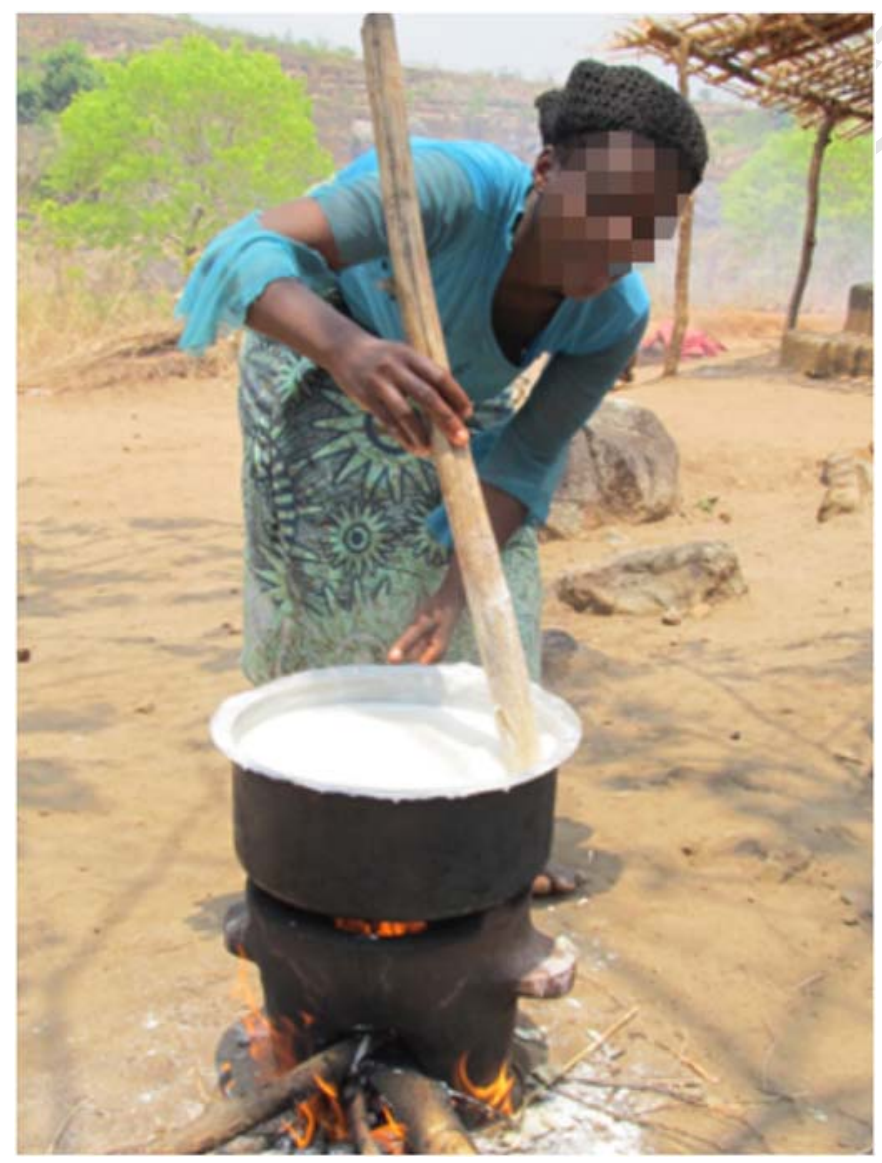

Fig. 2. Nsima (maize flour and water) preparation with a chitetezo mbaula cooking stove in Malawi.

this research. The manufacturing process takes places over several 262 days, and is depicted in Fig. 3. The main processes are as follows:

- Day 1: dry earth is collected then soaked in water overnight to form a 264 clay.

- Day 2: a paddle mould (cost 100 USD) is used to manufacture the 266 main shape of the stove after which details such as handles, pot 267 stand and holes for firewood and the TEG generator are added. They 268 are left to cure until dry.

- Day 3: wood is collected and the cured stoves are loaded into the kiln 270 and covered with a layer of clay and the kiln is fired. 271

- Day 4: the stoves are unloaded.

The TEG system

The TEG-stove generator system involves four main components; 275 the heat collector, the TEG module, the cooling system and the MPPT 276 conditioning circuitry. The heat collector design is based on previous 277 studies with the chitetezo mbaula (O'Shaughnessy et al., 2013, 2014, 278 2015a, 2015b). The collector comprises a $90 \mathrm{~mm} \times 90 \mathrm{~mm} \times 6 \mathrm{~mm} 279$ mild steel plate onto which three $12 \mathrm{~mm}$ diameter steel rods are 280 welded. A spacer is attached to the bottom of the rods to ensure that 281 they do not rest on the bottom of the combustion chamber. The purpose 282 of the rods is to act as a grate, compelling the user to position the fuel on 283 top of it thus allowing air to flow beneath and up through the fuel. This 284 air is preheated by the coals so that when it reaches the fire it improves 285 combustion (Bryden et al., 2005) and acts to reduce the build-up of 286 charcoal, which can act to insulate the TEG from the heat source. The 287 steel rods also conduct heat to the mounting plate onto which the hot 288 side of the TEG module is fixed.

289

The TEG is fastened between the heat collector plate and a water- 290 cooled aluminium heat sink, depicted in Fig. 4. As discussed in ref. 291 (Deasy, Baudin, O'Shaughnessy, \& Robinson, 2017) and depicted in 292 Fig. 5, the water-cooled heat sink has been designed using computa- 293 tional fluid dynamics (CFD), whereby the geometric parameters are 294 such that a sufficiently low thermal resistance is afforded with a 295 buoyancy-driven single phase thermosiphon system. To this end, the al- 296 uminium heat sink has a finned area of $40 \mathrm{~mm} \times 40 \mathrm{~mm}$ with $17 \mathrm{fins}, 297$ $1.6 \mathrm{~mm}$ fin spacing, $9 \mathrm{~mm}$ fin height and a fin thickness of $0.7 \mathrm{~mm} .298$ The finned area is positioned at the centre of a $2.4 \mathrm{~mm}$ thick base of di- 299 mensions $61 \mathrm{~mm} \times 58 \mathrm{~mm}$. The thermal resistance of the thermosiphon 300 system ranged between $0.068 \mathrm{~K} / \mathrm{W}$ and $0.099 \mathrm{~K} / \mathrm{W}$ depending on the 301 heat flux and the water temperature. This is considerably lower than 302 what would be afforded by a passive air cooling system.

303

The heat sink is sealed within an aluminium manifold. The manifold 304 is manufactured from a single block of aluminium of $30 \mathrm{~mm}$ thickness. A 305 cavity of $44 \mathrm{~mm} \times 44 \mathrm{~mm}$ cross-sectional area and a depth of $27 \mathrm{~mm}$ is 306 machined into the solid. Two holes are drilled and tapped at an angle of 307 $30^{\circ}$ to the outer face to accommodate two G1/4 male to $12 \mathrm{~mm}$ ID hose 308 fittings. This angle is chosen to allow the hole to intersect with the cavity 309 and to prevent the formation of air pockets which were observed to 310 form using horizontal connections. Pressure is applied to both sides of 311 the TEG by four M5 clamping bolts supported by spring washers and 312 nuts. The same torque $(0.75 \mathrm{Nm})$ is applied to each bolt using a narrow 313 range torque screwdriver. A sketch of the manifold and assembled gen- 314 erator is provided in Fig. 4.

The lower and upper barbed hose connections of the manifold are 316 connected to separate flexible braided PVC hoses which also connect 317 to a water reservoir with a maximum capacity of $9.5 \mathrm{l}$. The lower hose 318 supplies the manifold with cold water from the bottom of the reservoir 319 and is named the feed line. As heat is dissipated by the aluminium heat 320 sink to the water, temperature gradients are established in the water in- 321 side the manifold. This in turn causes density gradients in the liquid and 322 results in buoyancy-driven natural convection. The warmer water natu- 323 rally moves toward the upper regions of the manifold and exits through 324 the upper hose connection. The warm water is transported through the 325 


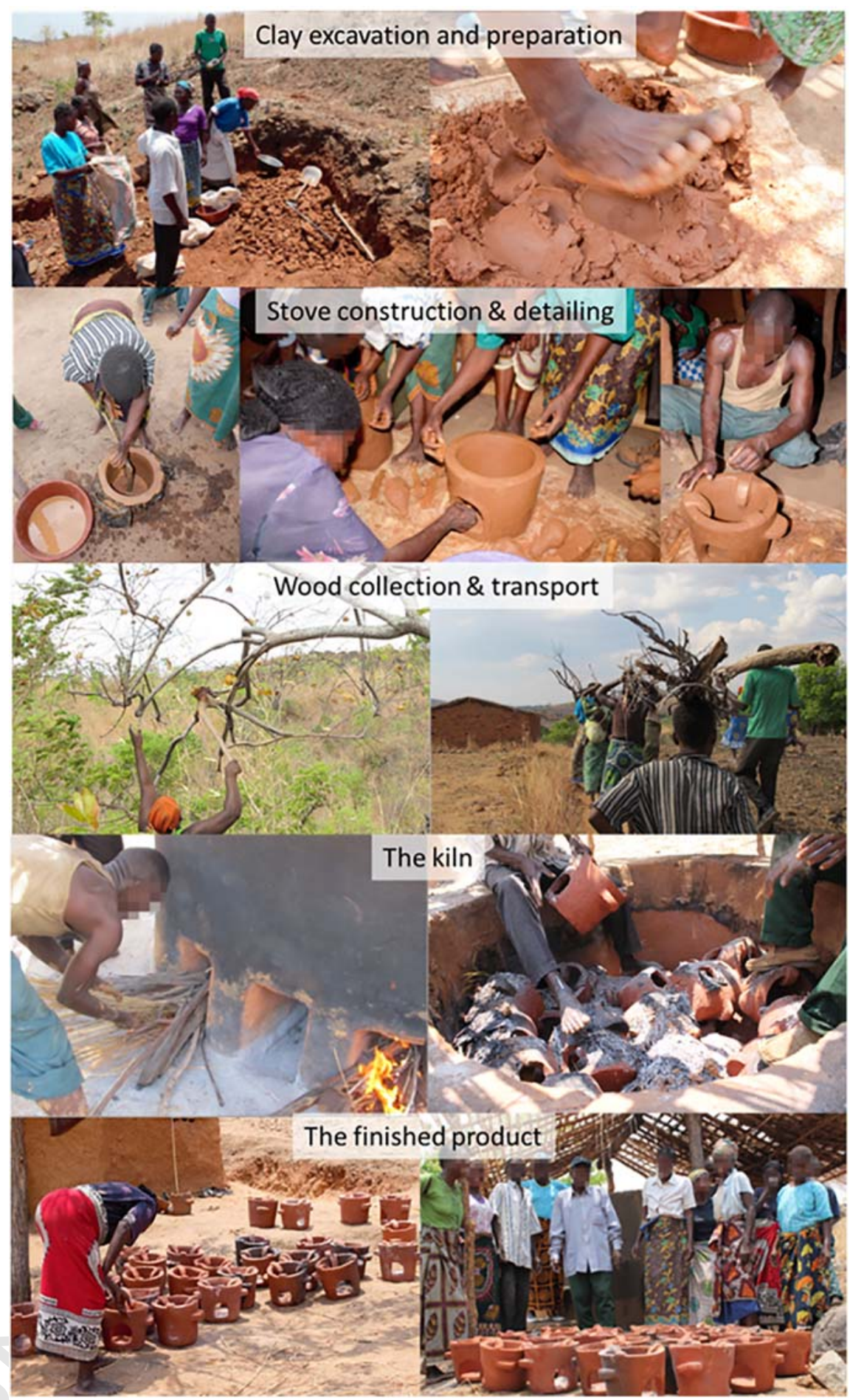

Fig. 3. Photographs of the stove manufacturing sequence.

upper pipe, named the return line, and back to the reservoir. Simultaneously the warm liquid leaving the manifold is replaced by cold fluid from the feed line. Since the cooling mechanism does not require any mechanical devices to drive the flow, it may be considered passive and since it operates in a loop i.e. it is a single phase thermosiphon. One key advantage of passive cooling is that it does not require electrical energy to drive the fluid motion, thus negating the requirement for mechanical devices such as pumps, which are expensive and susceptible to failure, and they draw from the limited power generated by the TEG (O'Shaughnessy et al., 2013). Furthermore, since fans are not employed and are therefore not powered from the TEG, the cooling system will continue to operate if there is a malfunction in the power control cir- 337 cuitry, unlike previous studies by the current authors (O'Shaughnessy 338 et al., 2014). This decouples the power conditioning circuit from the 339 cooling system operation and allows for troubleshooting, maintenance 340 and long term reliability.

The positioning of the reservoir and the connections are important 342 to the operation of the integrated passive cooling system. To establish 343 the thermosiphon effect, the reservoir must be positioned at a location 344 higher than the manifold, as shown in Fig. 5. Moreover, the location of 345 the connection of the return line to the reservoir should be below the 346 surface level of the water in the reservoir to avoid air entering the return 347 


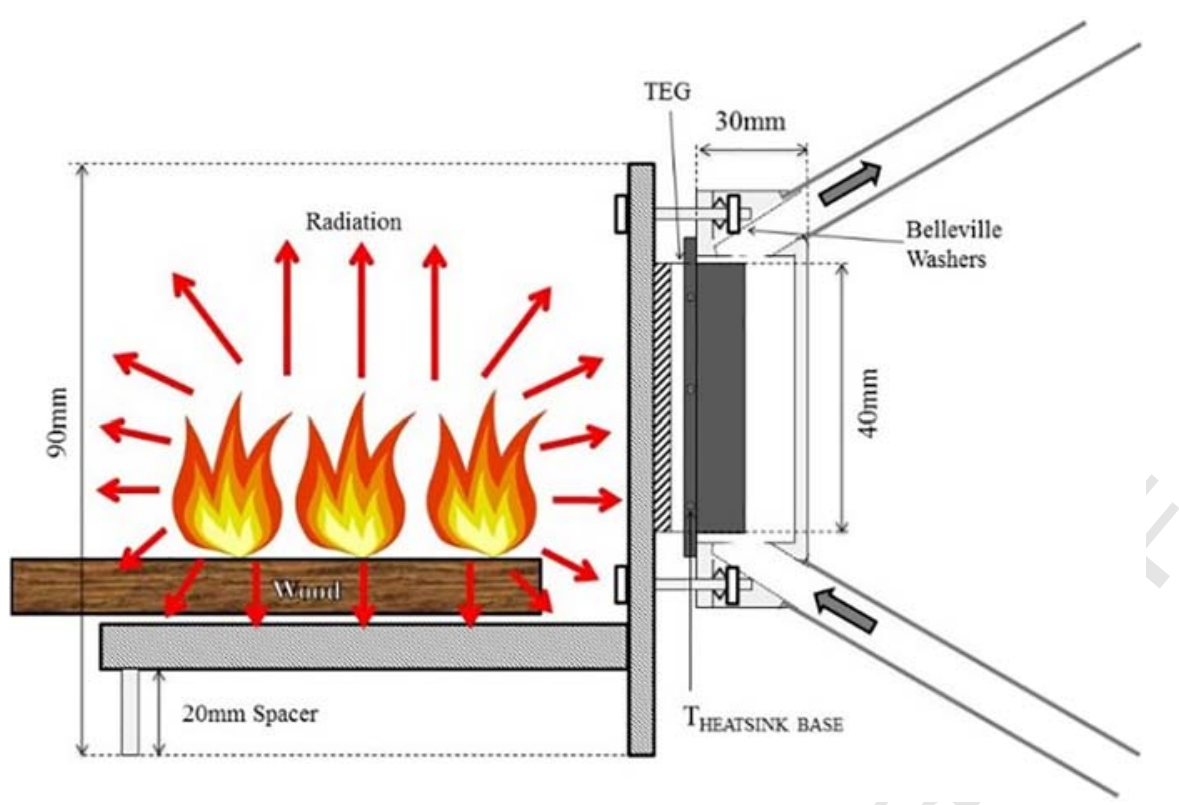

Fig. 4. The assembled unit.

line. The purpose of the reservoir is to act as a thermal store; i.e. to collect the thermal energy dissipated to the aluminium heat sink from the source. Previous in-field studies with this stove have indicated that the daily usage time for these stoves can vary greatly, and in many cases individual usage periods may be over $3 \mathrm{~h}$ in duration (O'Shaughnessy et al., 2014, 2015a, 2015b). The volume of water (9.5 l) in the reservoir is such that a significant amount of heat energy must be absorbed before the feed water experiences a considerable rise in temperature. In this way the temperature difference across the thermoelectric module can be maintained at reasonable levels for sustained periods, providing that the heat input and subsequent hot side temperature from the heat collector do not greatly exceed the recommended maximum levels for the TEG.

The reservoir is operated with an exposed surface, meaning some water is lost to the surroundings by evaporation. However, this also provides a path of low thermal resistance to the surroundings which is beneficial with regard to reducing the rate at which the reservoir temperature rises and is beneficial for maintaining a low cold side temperature of the TEG. For extended operation (>10 h (Deasy et al., 2017)), it may be necessary to replenish some of the liquid lost to evaporation so that the return line is always below the surface level of the water in the reservoir. This could also be mitigated by designing a reservoir to avoid such a problem. Of course, during extended operation the average temperature of the reservoir will increase, and the user could choose to 371 replace this warm water with colder water which will increase the 372 power output from the TEG system. Alternatively, the user will have a 373 source of warm water at the end of their meal preparation, which 374 could be used for other domestic purposes such as washing or cleaning. 375 In this situation the generator can be viewed as a cogeneration device. 376

Some of the design choices for the TEG-stove system in this study 377 were influenced by the desire to use commonly available components 378 such as hoses and buckets to act as reservoirs. The thermal performance 379 of the thermosyphon system depends on many aspects such as the 380 choice and geometry of the TEG module, the anticipated heat flow 381 through the TEG, the design of the heat sink and cooling block and the 382 volume and diameter of the reservoir. Thus, a general mathematical 383 model for system performance is not possible. However, a detailed 384 study on the effect of these parameters can be found in ref. (Deasy 385 et al., 2017) which can be used as a design guideline.

\section{MPPT conditioning circuitry}

For the MPPT circuit depicted in Fig. 6, a single-ended primary- 388 inductor converter (SEPIC) is employed to more efficiently avail of the 389 potential power when the TEG and load resistances are not matched. 390 A SEPIC allows the voltage at its output to be greater than, less than, 391

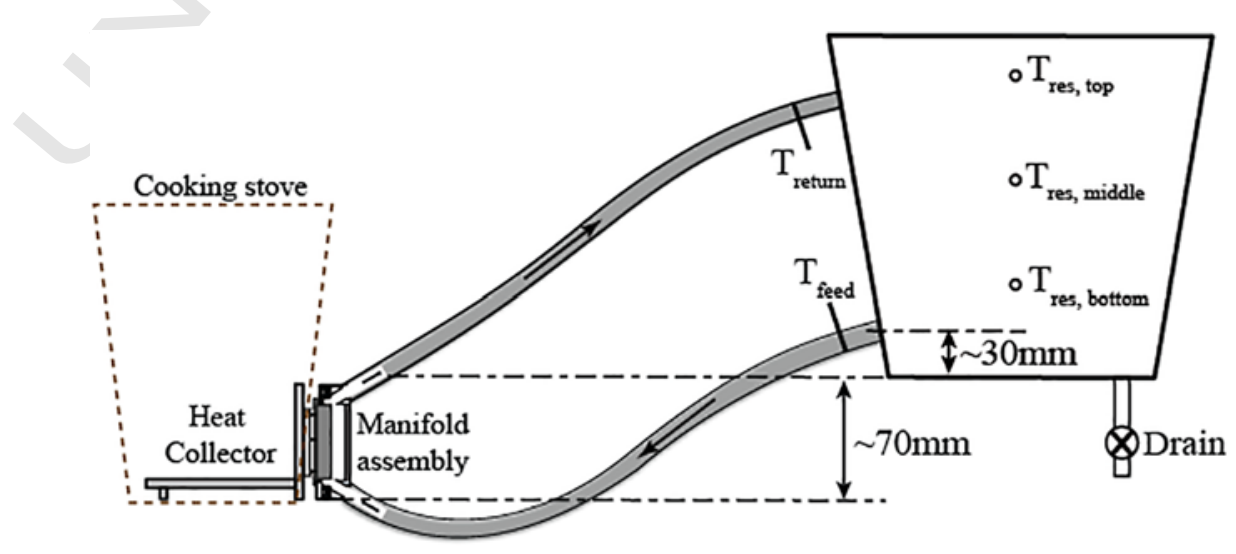

Fig. 5. Experimental setup. 


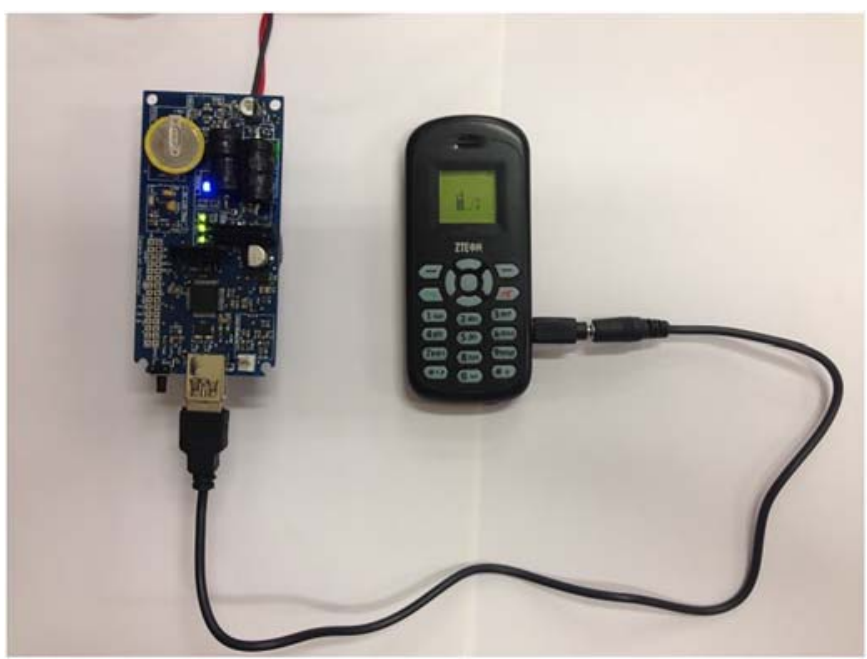

Fig. 6. Charging a ZTE-brand mobile phone using the SEPIC circuit.

or equal to that at its input. When a SEPIC is employed with a TEG as a power source, it electrically decouples the load resistance from the TEG's internal resistance. Maximum power can be achieved across a range of input resistances. This enables the direct conversion of power to a user's device without the need for an intermediate battery. The use of a power converter also provides flexibility, with scope for changing both the input (TEG) and the load (appliance).

The output of the SEPIC is controlled by the duty cycle of its control N-MOSFET. Here, the duty cycle is generated and modulated by a PIC24F micro-controller which is also employed for a number of auxiliary functions, including mode selection, data acquisition and logging, and data time stamping.

A maximum power point tracking algorithm is created based on the open circuit voltage method. Maximum power is produced when the input voltage, $V_{\mathrm{TEG}}$, is equal to half the open circuit voltage, $\mathrm{V}_{\mathrm{OC}}$. A disadvantage of this method is that it requires disconnecting the load from the input to measure the open circuit voltage. In this study, $\mathrm{V}_{\mathrm{OC}}$ is measured every $10 \mathrm{~s}$, with each measurement taking place $1.5 \mathrm{~ms}$ after the disconnection with the TEG.

The microcontroller constantly adjusts the duty cycle to maintain a stable voltage at the output of the circuit. If the input power is insufficient to achieve this target, the duty cycle is adjusted to maintain maximum output power. Maximum output power is determined by taking into account the MPP of the TEG as well as the efficiency of the circuit.

The input voltage is boosted by the SEPIC to a user-selectable output voltage ( $5 \mathrm{~V}$ or $4 \mathrm{~V}$ ) at the USB connection. When boosting to a fixed output voltage, the efficiency of the power converter increases with increasing input voltage. The circuit contains a mode select button which changes the set point voltage at the USB port. The mode is represented by an LED which changes colour in response to the user pressing the mode select button:

- Blue LED - $5 \mathrm{~V}$ output for mobile phones

- Green LED - $4 \mathrm{~V}$ output for radios

- Red LED - data access mode

To facilitate the measurement and acquisition of data pertaining to generator performance during laboratory and field trials, input and output power measurements are recorded by the microcontroller and saved to an on-board microSD card. The card can be disconnected from the circuit if necessary, but the data can also be accessed via the mode button and USB connection, in which case the card appears as an external storage drive. For field trials, the end users are trained to operate the circuit during the initial stove deployment, work which is carried out by the United Purpose field staff.
System cost estimates

The circuit described above contains many elements that may be 437 removed in a non-research environment, thus simplifying the circuit 438 design and reducing the overall cost significantly. For this system, esti- 439 mates are based on order volumes of 10,000 TEG-stove generators. 440 The main cost component is the TEG module, quoted at $\$ 8$ per module 441 from the supplier. The simplified circuit cost reduces substantially 442 with volume too, with an estimate of $\$ 4$ per circuit. The metallic compo- 443 nents, hoses and reservoir are estimated at $\$ 5$ per generator, the electri- 444 cal housing at $<\$ 2$ per generator and the electrical cabling at $<\$ 0.2$ per 445 generator. To make the TEG-stove system a viable alternative to other 446 power generating technologies, a target cost of $\sim \$ 25$ is envisaged.

\section{Laboratory experiments}

Whilst each of the components of the TEG-Stove system have been 449 tested separately, it is still deemed necessary to evaluate the complete 450 system performance under laboratory conditions.

\section{Experimental setup}

The generator system is installed into a modified chitetezo mbaula 453 stove which was manufactured as described in The cookstove. The 454 TEG-stove is investigated in a test centre in Ireland where a burn 455 laboratory, depicted in Fig. 7, has been designed and commissioned. 456 As the schematic shows, the TEG-stove is placed into a $1.0 \mathrm{~m}^{3}$ chamber 457 with transparent doors on all sides. Each door enables user access to the 458 stove and includes an air vent so that the stove can continue to burn fuel 459 with the doors closed. The stove rests on a bed of fire bricks to insulate 460 and prevent damage to the test facility. Above the stove is a fume hood 461

Extractor fan
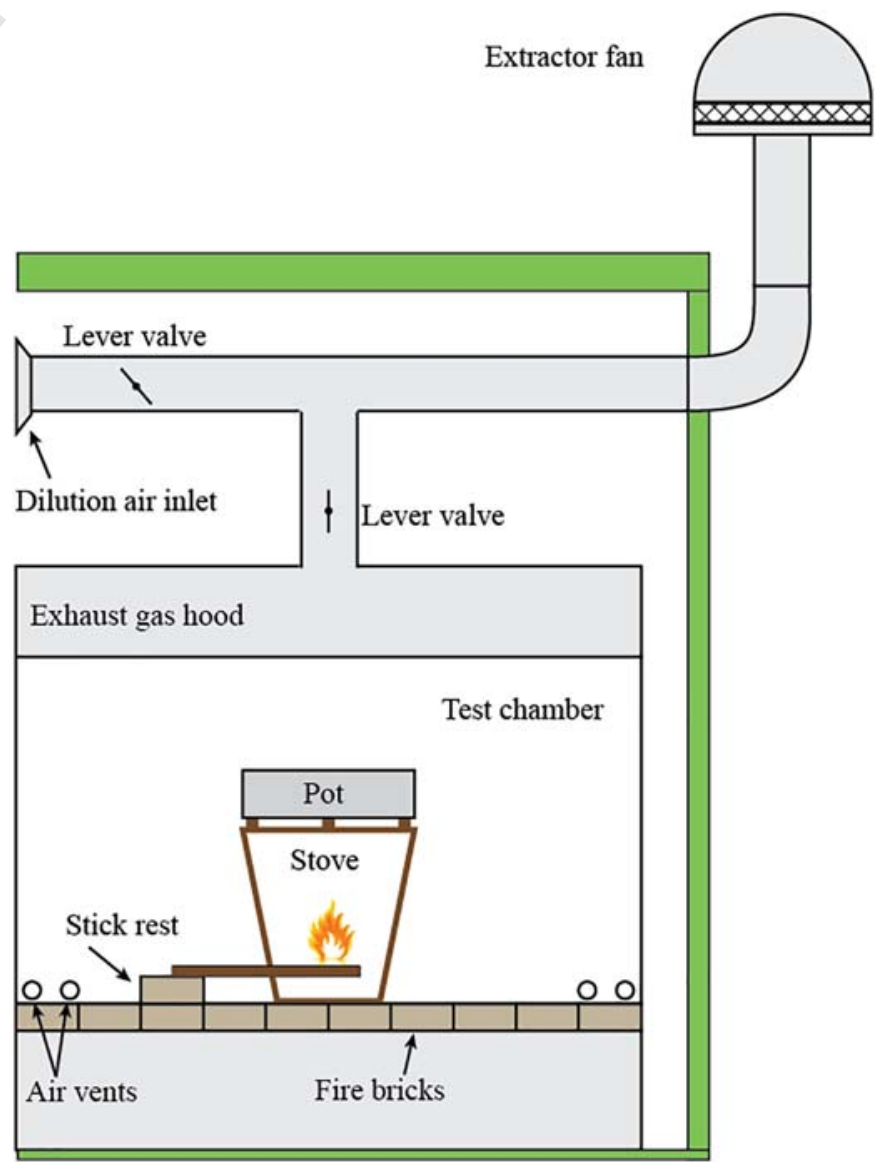

Fig. 7. Diagram of stove testing facility. 
that has been designed to capture and monitor the exhaust emissions if required. The fume hood is connected to a ducting system with interior dampers to prevent back drafts. The ducting can also draw fresh air from outside the test facility if desired. Exterior to the facility, a variablespeed extractor fan is employed to draw the exhaust gases and other emissions through the ducting and out of the building. The speed of the extractor fan has been set to ensure that it does not affect the normal operation and performance of the stoves under test.

\section{Experimental procedure}

An experiment commences by filling the reservoir with 9.51 of water at $20^{\circ} \mathrm{C}$. The manifold, feed and return lines are primed with water and checked for air pockets. A pot filled with water is placed on top of the stove to replicate practices observed in real life cooking scenarios. Wood from a single source is chopped into variable sizes whilst ensuring that three sticks can fit in the fuel entrance of the stove simultaneously, as per best practice for users of the chitetezo mbaula.

The fuel is ignited without accelerant and gradually burned, with infrequent stoking in order to emulate observations in earlier field trials. The initial fuel load is allowed to be reduced to charcoal before refuelling as this appears to be normal practice within the rural communities in Malawi. It has been observed over the course of numerous visits over different regions of Malawi that stove users frequently attend to other tasks (meal preparation, child minding, chores etc.) whilst cooking.

During a test, temperatures are recorded at $1 \mathrm{~Hz}$ at several locations in the stove and generator assembly. All thermocouple signals are acquired using National Instruments NI-DAQ9211 4-channel thermocouple data acquisition modules in conjunction with LabVIEW, and Type K, stainless steel, $1.5 \mathrm{~mm}$ diameter and $150 \mathrm{~mm}$ long grounded thermocouple probes. The temperatures in the region of the steel rods (i.e. the grate) and in the region of the flames are also recorded to give a qualitative measure of the heat source intensity. To enable the measurement of the approximate temperature difference across the TEG module during experiments, thermocouples are inserted into two $40 \mathrm{~mm} \times 40 \mathrm{~mm} \times 3$ $\mathrm{mm}$ copper plates that are placed either side of the TEG. The temperature at the inlet and outlet of the reservoir and at one location in the reservoir is also measured to monitor the cooling system performance. All thermocouples were calibrated against a F100 RTD probe with uncertainties of \pm $0.2{ }^{\circ} \mathrm{C}$ in the range $20-350{ }^{\circ} \mathrm{C}$.

The TEG voltage, TEG current, load voltage and load current are recorded at $1 \mathrm{~Hz}$ using a National Instruments NI-DAQ9219 data acquisition module. To enable LabVIEW current measurements, a precision $0.03 \Omega$ sense resistor is placed between the TEG and circuit input, and between the load and circuit output. These measurements are also recorded on-board the power control circuit. This dual measurement enables verification of important electrical data recorded by the circuit.

The circuit is connected via the USB port to a BK Precision 8540 Electronic Load set to control voltage mode. The circuit mode is set to $5 \mathrm{~V}$ output mode, as indicated by the blue LED. In many instances where devices such as mobiles phones are charged from a power-limited source, the charging voltage is actually lower than $5 \mathrm{~V}$ and is linked to the voltage of the internal battery of the particular device. This frequently occurs when charging from USB ports on PCs or laptops, where the current is limited to $500 \mathrm{~mA}$. In these cases, the actual charging voltage can vary from $3.7 \mathrm{~V}$ to $5 \mathrm{~V}$. For this reason, the electronic load was set to draw power from the circuit at a mid-range value of $4.5 \mathrm{~V}$.

\section{Results and discussion}

\section{Laboratory experiments}

Several laboratory experiments have been performed with the TEGstove system. Due to the stochastic nature of fuel burning, somewhat different results are obtained for each experiment though the general trends are adequately close to one another to have confidence in the repeatability and efficacy of the measurements. The results presented 523 in this section are provided as an example and relate to one particular 524 experiment during which the TEG-stove was operated for approxi- 525 mately $5 \mathrm{~h}$. Usage periods of this duration have been frequently 526 measured in previous field trials (O'Shaughnessy et al., 2014). For this 527 example and all other experiments, the fuel is allowed to burn to char- 528 coal before the addition of more wood to the combustion chamber. In 529 this example, fresh fuel is added at approximately $2.5 \mathrm{~h}$.

Fig. 8 shows the temperature recorded on either side of the TEG 531 module along with the associated temperature differential across it. 532 Several important features are immediately apparent. After an initial in- 533 crease immediately after the fire is ignited, the cold side temperature 534 quickly rises to the region of $50{ }^{\circ} \mathrm{C}$ and remains quite constant. The 535 hot side of the TEG module also rises quickly to $250{ }^{\circ} \mathrm{C}$ and subsequently 536 fluctuates in accordance with the fluctuations in local temperature 537 in the combustion chamber of the stove. These fluctuations can be 538 naturally occurring, or may be attributed to the occasional stoking of 539 the fuel. These fluctuations are responsible for those seen in the TEG 540 temperature difference since the cold side temperature remains rela- 541 tively stable throughout the test interval.

The aluminium heat sink is cooled by a supply of low temperature 543 water as shown in Fig. 9. Although the return line water experiences 544 an initial rapid rise in temperature once heat transfer through the heat 545 sink is initiated, the thermal mass of the reservoir ensures that cool 546 water is supplied for almost $1 \mathrm{~h}$ before any significant rise in feed 547 water temperature, and this had the effect of moderating the return 548 line temperature which plateaus as well. This phenomena is discussed 549 in more detail in a previous study (Deasy et al., 2017). After this initial 550 quasi-steady period, both feed line and return line temperatures begin 551 to rise and again plateau after about $3 \mathrm{~h}$ as evaporation from the 552 exposed free surface of the water reservoir, and to a lesser extent 553 convection from the reservoir walls, transfers heat to the ambient. The 554 return line temperature exhibits low magnitude fluctuation due to 555 those of the TEG hot side temperature.

The electrical power generated by the TEG is plotted in Fig. 10 which 557 also shows the power consumed by the electronic load and the circuit 558 efficiency. The efficiency is calculated as the ratio of the measured 559 power supplied to the electronic load to that generated by the TEG sub- 560 sequent to the MPPT circuitry. The input power reflects the temperature 561 difference across the TEG module, and displays an identical pattern to 562 that seen in Fig. 8. Since the circuit efficiency is relatively constant, 563 $\sim 70 \%$ when the input power is above $1 \mathrm{~W}$, the output and input power 564 follow the same trend. A maximum power supply to the electronic 565 load of 3.8 W was achieved, corresponding to a maximum power gener- 566 ation of approximately $5.8 \mathrm{~W}$. The largest power output is obtained at 567 the early stages of the burn associated with the time interval when 568 the TEG temperature difference is greatest (see Fig. 8). Since the feed 569 water temperature increases over time, an expected drop in output 570

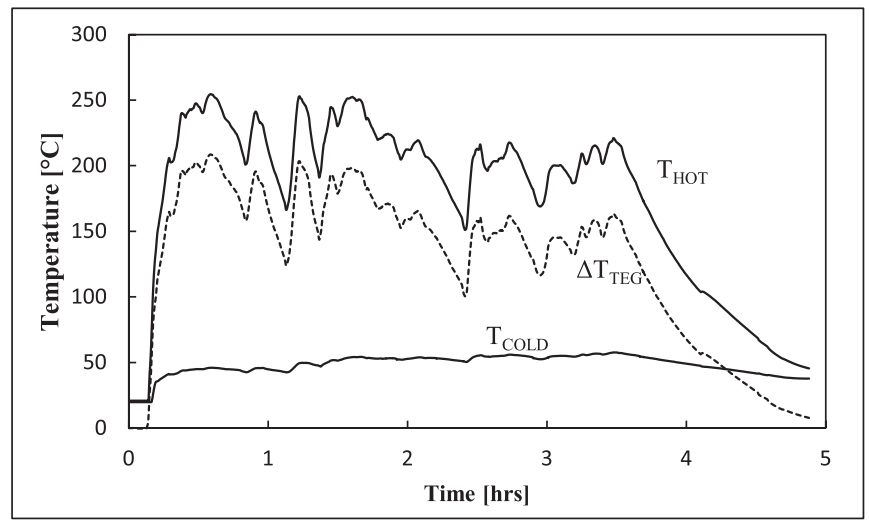

Fig. 8. TEG temperatures during experiment 


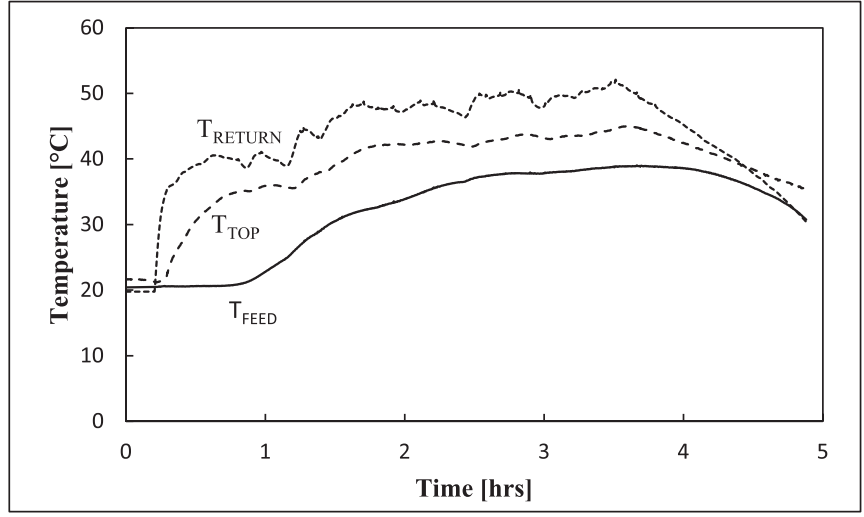

Fig. 9. Water temperatures during test.

power is observed, though this drop is also linked to the general reduction in hot side temperature after $2.5 \mathrm{~h}$ as well.

From Fig. 10 it is noted that the delivered power is typically above $2.5 \mathrm{~W}$. A large range of devices can be charged from a USB port at a nominal $5 \mathrm{~V}$ and a maximum current of $500 \mathrm{~mA}$. Examples of such devices which have been observed by the authors in rural developing world communities are mobile phones, portable radios, LED lights and lanterns, portable battery packs, ultra-violet water sterilizers and portable fans.

Fig. 11 plots the input and output voltage and current throughout the duration of the test. The input voltage fluctuates with $\Delta \mathrm{T}_{\mathrm{TEG}}$ but the output voltage remains stable at the set point voltage for the electronic load.

In the context of the power output for charging low powered electronics appliances such as phones, LED lanterns and radios, it should be noted that this level exceeds that of a USB port on a laptop computer, which provides a maximum $2.5 \mathrm{~W}$ at $5 \mathrm{~V}$.

The TEG continues to produce usable power until just over $4 \mathrm{~h}$, at which point the input power is insufficient to maintain $5 \mathrm{~V}$ at the circuit output and the power control circuitry engages a sleep mode. Over the duration of the experiment, a total of $14.6 \mathrm{~W} \cdot \mathrm{h}$ is generated and 9.9 $\mathrm{W} \cdot \mathrm{h}$ is delivered to the electronic load, as shown in Fig. 12. This is the energy that would be available for device charging and is more than sufficient for general use of low powered devices (O'Shaughnessy et al., 2014, 2015b). Also shown in Fig. 12 is a comparison between the data measured on-board the circuit (which will subsequently be used for field trial generator performance evaluation) and that measured externally via the DAQ hardware and LabVIEW. The data shows excellent agreement, with the total power integrals agreeing to within $0.1 \%$ and $2.9 \%$ for the input and output power respectively. This demonstrates

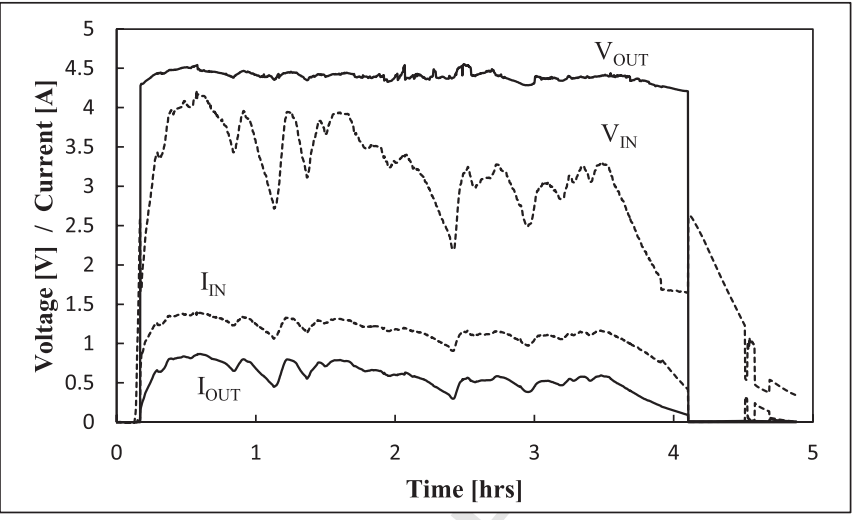

Fig. 11. Input and output voltage and current as measured by LabVIEW.

that the on-board data logging capability can be used for reliable mea- 601 surements in the field.

The production and delivery of approximately $10 \mathrm{~W} \cdot \mathrm{h}$ of power 603 over the course of $4 \mathrm{~h}$ is sufficient power to charge most smart phones 604 and larger LED lamps. This will more than meet the minimum daily 605 needs of $5 \mathrm{~W} \cdot \mathrm{h}$ per day from normal usage of the stove. The output of 606 $2.5 \mathrm{~W}$ on average is consistent with power level at which many devices 607 charge. In this regard, the output of the TEG-stove system was deemed 608 adequate for DC charging of low powered devices and was thus suitable 609 for field trials.

Preliminary field testing

A total of five generators were produced, assembled and tested in 612 TCD before being sent to Malawi. The completed generator unit and cir- 613 cuit were integrated with modified Malawi-made chitetezo mbaula by 614 United Purpose field staff. The field staff were responsible for sourcing 615 local water reservoirs (plastic buckets), attaching and positioning the 616 fittings and hosing and sealing the generator into the stove with fresh 617 clay. The completed TEG-Stoves, an example of which is shown in 618 Fig. 13, were then distributed to five families in three separate areas 619 for testing. Stove, circuit and reservoir operating instructions were pro- 620 vided to the users of the generators. USB phone cables and a portable 621 power bank were also supplied with each generator.

The data was collected from the circuits after several days of opera- 623 tion along with user feedback. The operation of the TEG-Stove has not 624 yet caused any negative technical issues or crossed any unforeseen 625 social-cultural boundaries. The TEG-stoves usage hours are similar to 626 those recorded in previous field trials (O'Shaughnessy et al., 2013, 627 2014, 2015b), with daily usage patterns of between 2 and $8 \mathrm{~h}$.

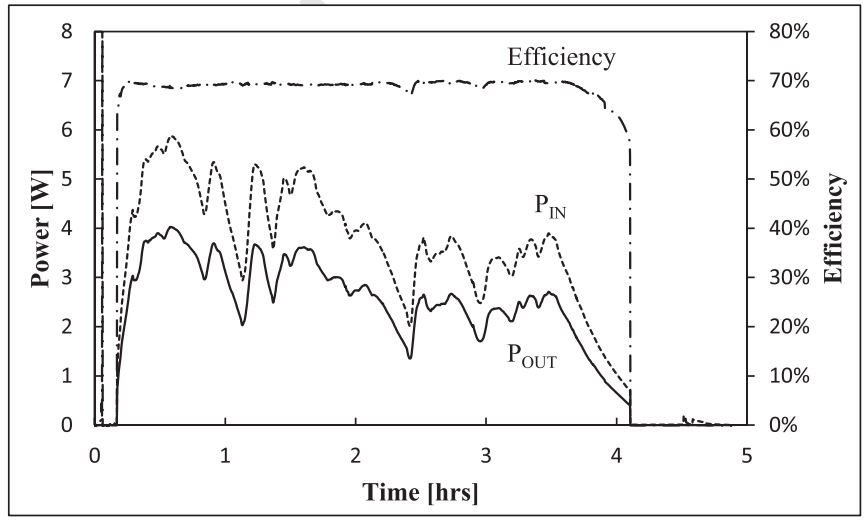

Fig. 10. Power generated and supplied and circuit efficiency during test.

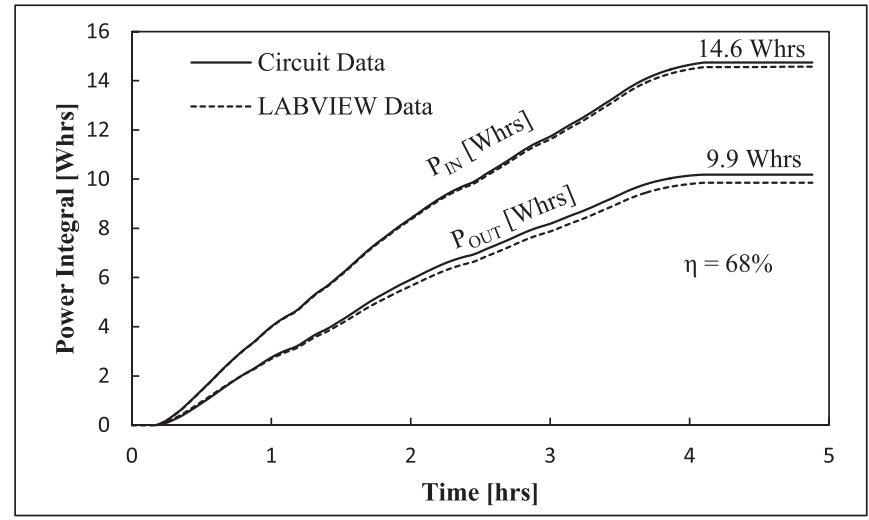

Fig. 12. Input and output power integrals as measured by the TEG circuit and LabVIEW. 


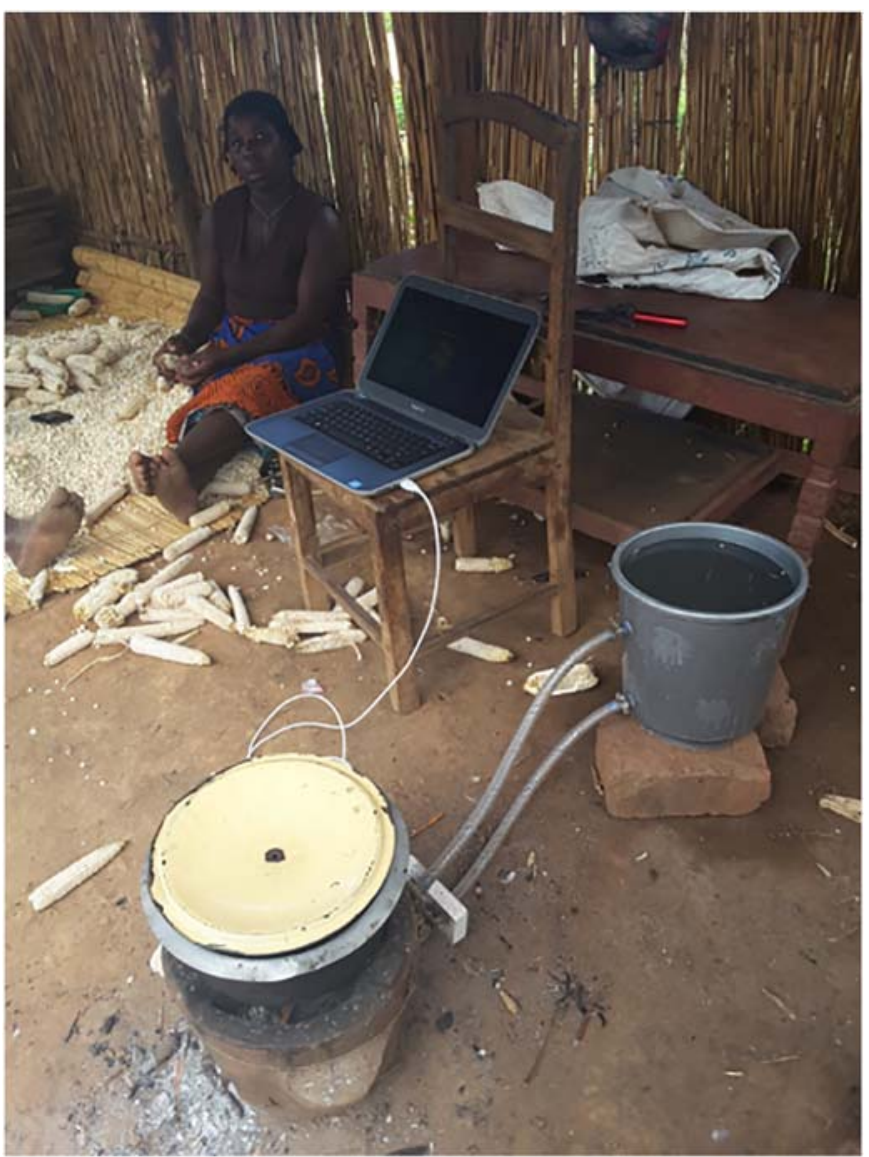

Fig. 13. TEG-Stove in operation in Malawi.

Fig. 14 shows a daily power profile from a volunteer Malawian family using the prototype TEG-stove, and is very typical of the profiles measured across all stoves deployed in the field trial so far. The figure overlays the measured power generated by the TEG and the measured power consumed by the user's device. It must be noted that the power levels achieved in the field were lower when compared with laboratory experiments (cf. Fig. 10), which can be attributed to infrequent tending to the stove along with other factors such as using non-ideal wood or crop-waste fuel which can result in a lower temperature difference 637 across the TEG. The higher ambient temperature in Malawi also results 638 in a higher average operating temperature which adversely affects 639 power output (Deasy et al., 2017).

Fig. 14 also plots the open circuit voltage, which is clearly correlated 641 to the power. In this example, the users operated the TEG stove for 642 almost $3 \mathrm{~h}$, most likely for the breakfast meal. Interestingly, the users 643 did not choose to connect any device during the first 40 min of opera- 644 tion, despite this being the period with the greatest available power. 645 During this phase, the TEG is effectively in the open-circuit condition, 646 except for the small amount of power required to run circuit features 647 such as the LED and data logging. At approximately 07:09, a device is 648 connected to the circuit and the on-board measurements are logged to 649 the SD card. In this case, the user's device draws almost the maximum 650 power available to it, at approximately 65-70\% efficiency for the major- 651 ity of the charge.

\section{Conclusion}

This study describes the design, construction and testing of a com- 654 plete TEG-stove system, with the target users being those in households 655 in the developing world where electricity access for low powered 656 electronic devices is problematic. The complete system involves the 657 manufacture of a portable clay improved cookstove, a heat collector, 658 TEG system, passive liquid cooled heat sink and MPPT circuitry. The 659 aboratory trials resulted in a stable output of $\sim 2.5 \mathrm{~W}$ at $5 \mathrm{~V}$ via a USB 660 connection. The laboratory experiments also showed that the heat 661 collector and cooling system can maintain the maximum temperature 662 of the TEG to below the manufacturer's recommended threshold. 663 Importantly, the simple and low cost single-phase thermosiphon 664 cooling system can maintain the temperature of the cold side of a single 665 TEG module at adequately low temperatures for sustained periods. 666 Over the course of a five hour long laboratory-based experiment, the 667 generator produced a maximum of $5.8 \mathrm{~W}$, with a total energy output 668 of $14.6 \mathrm{~W} \cdot \mathrm{h}$. The magnitude of the power generated by this passive 669 cooling system was observed to be comparable to that delivered by sim- 670 ilar TEG-stove systems driven by active cooling. Using a specifically 671 designed power control circuit with an efficiency of $\sim 70 \%$, the usable 672 energy was $\sim 10 \mathrm{~W} \cdot \mathrm{h}$ for charging. Thus, the laboratory trials showed 673 that the system can be used to charge a variety of appliances that are 674 powered by $5 \mathrm{~V}$ supplies such as mobile phones, LED lights, radios and 675 rechargeable batteries and fields trials ensued.

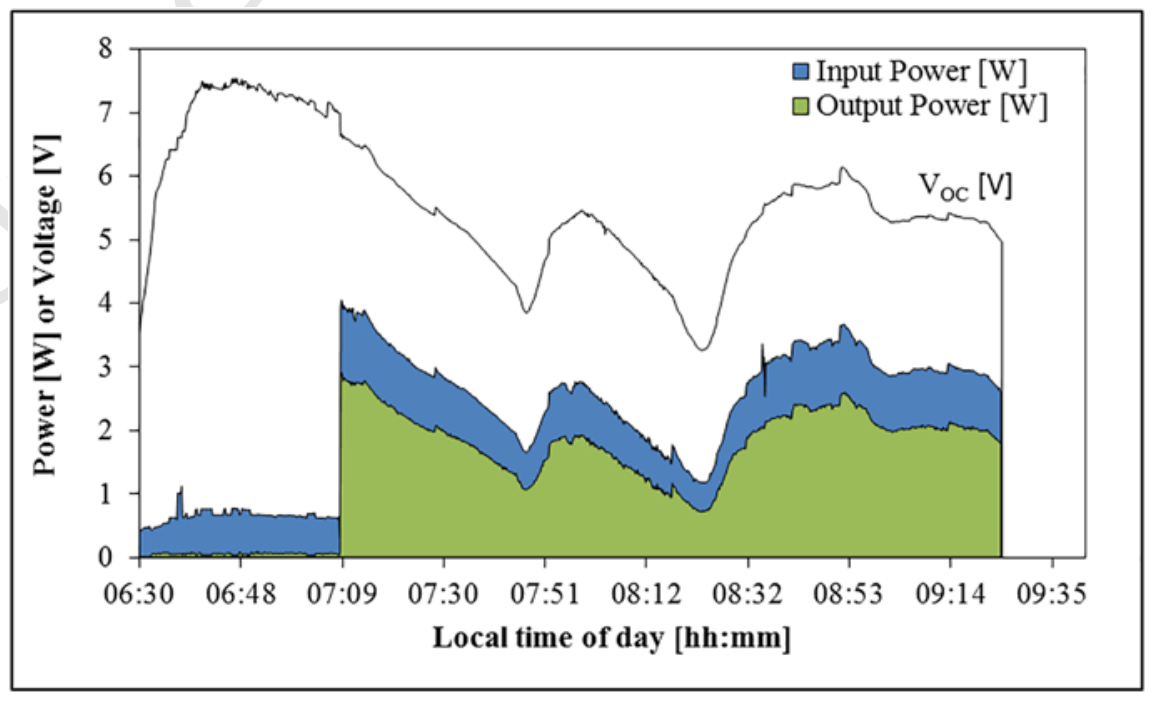

Fig. 14. Measured TEG parameters during user operation of Stove B in the Thyolo field trial. 
Prototypes were disseminated to 5 disparate volunteer households in the Thyolo district of Malawi, Africa. Preliminary field trial data shows promising results, with the generators being regularly used for charging and appearing to provide electrical energy when required. In-field power production is determined to be slightly below laboratory levels, which demonstrates that data measurement and collection is vital to the iterative design process. Even under-performing, the TEG-stove appears to provide adequate base-load electrical energy for the target demographic in Malawi. Future work will target improvement of performance by analysing the heat collection and cooling methods, based on the results obtained over a longer duration of the field trial.

\section{Acknowledgments}

The authors wish to acknowledge the significant contribution from Irish Aid to this research, and the ongoing collaboration with United Purpose Malawi (formerly Concern Universal Malawi). We also wish to express our gratitude to Luke Robinson who contributed his expertise in photography to the study.

\section{References}

Brazdil, M., \& Pospisil, J. (2013). Thermoelectric power generation utilizing the waste heat from a biomass boiler. Journal of Electronic Materials, 42, 2198-2202.

Bryden, M., Still, D., Scott, P., Hoffa, G., Ogle, D., Bailis, R., et al. (2005). Design principals for wood burning cook stoves: Aprovecho research center.

Champier, D., Bedecarrats, J. P., Kousksou, T., Rivaletto, M., Strub, F., \& Pignolet, P. (2011). Study of a TE (thermoelectric) generator incorporated in a multifunction wood stove. Energy, 36, 1518-1526.

Champier, D., Bedecarrats, J. P., Rivaletto, M., \& Strub, F. (2010). Thermoelectric power generation from biomass cook stoves. Energy, 35, 935-942.

Deasy, M. J., Baudin, N., O'Shaughnessy, S. M., \& Robinson, A. J. (2017). Simulation-driven design of a passive liquid cooling system for a thermoelectric generator. Applied Energy, 205, 499-510.

Elghool, A., Basrawi, F., Ibrahim, T. K., Habib, K., Ibrahim, H., \& Idris, D. M. N. D. (2017). A review on heat sink for thermo-electric power generation: Classifications and parameters affecting performance. Energy Conversion and Management, 134, 260-277.

Gao, H. B., Huang, G. H., Li, H. J., Qu, Z. G., \& Zhang, Y. J. (2016). Development of stove-powered thermoelectric generators: A review. Applied Thermal Enoineering 96, 297-310.

Goudarzi, A. M., Mazandarani, P., Panahi, R., Behsaz, H., Rezania, A., \& Rosendahl, L. A (2013). Integration of thermoelectric generators and wood stove to produce heat. Hot Water, and Electrical Power, 1-7.

Högblom, O., \& Andersson, R. (2016). A simulation framework for prediction of thermoelectric generator system performance. Applied Energy, 180, 472-482.

Hsu, C. T., Huang, G. Y., Chu, H. S., Yu, B., \& Yao, D. J. (2011). An effective Seebeck coefficient obtained by experimental results of a thermoelectric generator module. Applied Energy.
Killander, A., \& Bass, J. C. (1996). A stove-top generator for cold areas. Fifteenth international 720 conference on thermoelectrics proceedings ICT '96, 26-29 March 1996 (pp. 390-393). 721 New York, NY, USA: IEEE

Kinsella, C. E., O'Shaughnessy, S. M., Deasy, M. J., Duffy, M., \& Robinson, A. J. (2014). 723 Battery charging considerations in small scale electricity generation from a thermoelec- 724 tric module. Applied Energy, 114, 80-90. 725

Lertsatitthanakorn, C. (2007). Electrical performance analysis and economic evaluation of 726 combined biomass cook stove thermoelectric (BITE) generator. Bioresource Technology, 727 98, 1670-1674.

Mastbergen, D., Willson, B., \& Joshi, S. (2005). Producing light from stoves using a thermo- 729 electric generator. Ethos, 2005

Nuwayhid, R. Y., \& Hamade, R. (2005). Design and testing of a locally made loop-type 731 thermosyphonic heat sink for stove-top thermoelectric generators. Renewable 732 Energy, 30, 1101-1116.

Nuwayhid, R. Y., Moukalled, F., AbuSaid, R., \& Daaboul, M. (2000). Practical design consider- 734 ations for a rural stove-top thermoelectric generator. Proceedings of 19th international 735 conference on thermoelectrics (ICT2000). Cardiff, Wales: Babrow, Wales. 736

Nuwayhid, R. Y., Rowe, D. M., \& Min, G. (2003). Low cost stove-top thermoelectric generator 737 for regions with unreliable electricity supply. Renewable Energy, 28, 205-222. 738

Nuwayhid, R. Y., Shihadeh, A., \& Ghaddar, N. (2005). Development and testing of a 739 domestic woodstove thermoelectric generator with natural convection cooling. 740 Energy Conversion and Management, 46, 1631-1643.

O'Shaughnessy, S. M., Deasy, M. J., Doyle, J. V., \& Robinson, A. J. (2014). Field trial testing of 742 an electricity-producing portable biomass cooking stove in rural Malawi. Energy for 743 Sustainable Development, 20,1-10. 744

O'Shaughnessy, S. M., Deasy, M. J., Doyle, J. V., \& Robinson, A. J. (2015a). Adaptive design of 745 a prototype electricity-producing biomass cooking stove. Energy for Sustainable 746 Development, 28, 41-51. 747

O'Shaughnessy, S. M., Deasy, M. J., Doyle, J. V., \& Robinson, A. J. (2015b). Performance anal- 748 ysis of a prototype small scale electricity-producing biomass cooking stove. Applied 749 Energy, 156, 566-576.

O'Shaughnessy, S. M., Deasy, M. J., Kinsella, C. E., Doyle, J. V., \& Robinson, A. J. (2013). Small 751 scale electricity generation from a portable biomass cookstove: Prototype design and 752 preliminary results. Applied Energy, 102, 374-385.

Qiu, K., \& Hayden, A. C. S. (2011). Development of thermoelectric self-powered heating 754 equipment. Journal of Electronic Materials, 1-5. 755

Raman, P., Ram, N. K., \& Gupta, R. (2014). Development, design and performance analysis 756 of a forced draft clean combustion cookstove powered by a thermo electric generator 757 with multi-utility options. Energy, 69, 813-825.

Rowe, D. M. (1978). Thermoelectric power generation. Proceedings of the Institution of 759 Electrical Engineers, 125, 1113-1136.

Rowe, M. D., Gao, M., Williams, S. G. K., Aoune, A., Matsuura, K., Kuznetsov, V. L., et al. (1997). 761 Thermoelectric recovery of waste heat-case studies. IECEC-97 proceedings of the thirty- 762 second intersociety energy conversion engineering conference (Cat No97CH6203), vol. 2. 763 (pp. 1075-1079).

Stokes, D., Mantini, M., Chartier, R., \& Rodes, C. (2012). Design and testing of a Thermo- 765 electric Enhanced Cookstove Add-on (TECA) for indigenous biomass stoves in 766 Kenya. 10th international conference on healthy buildings 2012, July 8, 2012-July 12, 767 2012 (pp. 477-482). Brisbane, QLD, Australia: International Society of Indoor Air 768 Quality and Climate. 